\title{
A Circularly Polarized HTS Microstrip Antenna Array with Controllable Cryostat
}

\author{
Xiaoyong Zeng, Kama Huang, Zhongxia Hu, Qian Chen, and Wei Xiao \\ College of Electronics and Information Engineering, Sichuan University, Chengdu, China \\ Correspondence should be addressed to Kama Huang; kmhuang8779@163.com
}

Received 13 April 2017; Revised 10 June 2017; Accepted 20 June 2017; Published 20 July 2017

Academic Editor: N. Nasimuddin

Copyright (c) 2017 Xiaoyong Zeng et al. This is an open access article distributed under the Creative Commons Attribution License, which permits unrestricted use, distribution, and reproduction in any medium, provided the original work is properly cited.

\begin{abstract}
A high-temperature superconductor (HTS) microstrip antenna array with right-hand circular polarization is proposed for space communications. The proposed HTS antenna array can achieve high efficiency, which is able to reduce the antenna's loss. The array consists of 16 antenna elements being fed by a T-network. A pair of symmetric meander slots is used in each antenna element to broaden the input matching bandwidth. A controllable cryostat is used as the refrigeration for HTS. The experiment shows that the gain of the proposed HTS antenna is $8.39 \mathrm{~dB}$, whose $10 \mathrm{~dB}$ return loss bandwidth is $2.2 \%$ ranging from $5.75 \mathrm{GHz}$ to $5.87 \mathrm{GHz}$. In comparison with a traditional conductor antenna array having the same configuration, the proposed array has an $8.1 \mathrm{~dB}$ improvement in the gain and a $69.2 \%$ enhancement in the radiation efficiency.
\end{abstract}

\section{Introduction}

Antenna is an important component for space communication, where some characteristics of the antennas are highly desired, including high gain, high efficiency, low profile, and low cost [1]. The microstrip antenna array having the advantages of high gain and low profile and the convenience of fabrication is considered as a good candidate [2,3]. However, due to the conductor loss, the microstrip antenna suffers from relatively low efficiency, especially in antenna arrays with feed networks [3].

In order to overcome this defect, the high-temperature superconductor (HTS) with low conductor loss has been used in antennas for high efficiency [4-11]. The use of the HTS in the antenna can lead to the reduction of the loss of the matching circuit and feed network, which is proportional to the conductor loss $[2,3]$. Besides, the HTS is able to suppress the undesirable surface-wave of the antenna, thus increasing the radiation efficiency [4]. For example, the work [5] proposed a miniaturized HTS microstrip patch antenna, which achieved the good radiation efficiency between $35 \%$ and $65 \%$. In [6], a HTS helical antenna was designed, and its efficiency is $70 \%$. Reference [7] proposed a HTS antenna array with a measured gain of $1.54 \mathrm{~dB}$

Usually, the working temperature of the HTS is about $80 \mathrm{~K}$, and thus a cryostat should be created for the HTS antenna. In traditional designs [4-11], liquid nitrogen is used for the cryostat. Yet, the liquid nitrogen should be refreshed continuously for stable temperature, so it is hard to control the temperature accurately. Different from the liquid nitrogen, a new commercial Stirling refrigerator has the ability to accurately control the temperature from $60 \mathrm{~K}$ to $300 \mathrm{~K}$ by computers, which is more suitable and affordable as the cryostat for the HTS antenna.

In this paper, a HTS microstrip antenna array with righthand circular polarization is designed at $5.8 \mathrm{GHz}$. It is fabricated with $\mathrm{D}_{\mathrm{y}} \mathrm{BCO}$ on a $\mathrm{LaAlO}_{3}$ substrate by thermal coevaporation. The array is comprised of 16 antenna elements being fed by a T-network. In the antenna, two truncated corners are used to generate the circular polarization, and a pair of symmetric meander slots is used to broaden the input matching bandwidth. A Stirling refrigerator is employed as the controllable cryostat. Compared with a traditional conductor antenna with the same configuration, the HTS antenna array has high radiation efficiency. 


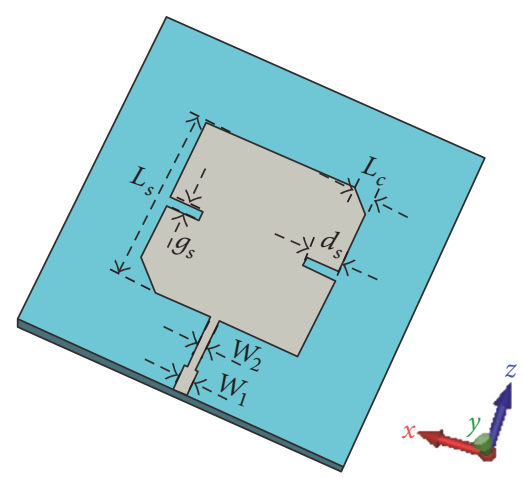

FIGURE 1: The configuration of the HTS antenna array's element.

\section{Design of the HTS Antenna Array}

2.1. Design of the Antenna Element. Figure 1 depicts the configuration of the HTS antenna array's element, which is a square microstrip antenna. Two truncated corners and a pair of symmetric slots are etched for the circular polarization and broad input matching bandwidth, respectively. The substrate is made of $\mathrm{LaAlO}_{3}$ having a thickness of $0.5 \mathrm{~mm}$ with the relative permittivity of 24 .

According to [2], the square patch will create a resonance, whose frequency $f_{1}$ can be calculated by

$$
f_{1}=\frac{c}{2 L_{s} \sqrt{1+\varepsilon_{r}}}
$$

where $c$ is the speed of the light in free space, $L_{s}$ is sidelength of the square, and $\varepsilon_{r}$ is the relative permittivity of the substrate. With the truncated corners, another orthogonal resonance will be created [7]. Correspondingly, the resonance frequency $f_{2}$ can be expressed as

$$
f_{2}=f_{1}\left(1-\frac{L_{c}^{2}}{L_{s}^{2}}\right),
$$

where $L_{s}^{2}$ is the area of the square patch and $L_{c}^{2}$ is the area of the two truncated corners. $f_{1}$ and $f_{2}$ are set to close properly, and hence the frequency band between them can be with the circular polarization.

Due to the high permittivity and thin thickness of the substrate, a high quality factor of the antenna is obtained. Thus the input matching bandwidth is narrow, only ranging from $0.85 \%$ to $1.1 \%$ [11]. In order to improve the bandwidth of the antenna, a pair of symmetric meander slots is etched on the patch, and hence two new resonance modes $\mathrm{TM}_{20}$ and $\mathrm{TM}_{30}$ are created [12]. With the proper dimension of slots, the frequency of $\mathrm{TM}_{20}$ and $\mathrm{TM}_{30}$ is adjacent, so the input matching bandwidth can be broadened. Besides, $d_{s}$ and $g_{s}$ are the length and width of the slot, respectively, which are obtained by sweeping parameters with the CST Microwave Studio, a popular full-wave simulator. The feed line for the antenna is with an impedance of $100 \Omega$ and $W_{l}$ is the width of the feed line. The optimized parameters values are listed in Table 1 .
TABLE 1: Parameters of the antenna element.

\begin{tabular}{lc}
\hline Parameter & Value $(\mathrm{mm})$ \\
\hline$L_{s}$ & 5.27 \\
$L_{c}$ & 0.59 \\
$D_{s}$ & 1.80 \\
$G_{s}$ & 0.18 \\
$W_{l}$ & 0.17 \\
\hline
\end{tabular}

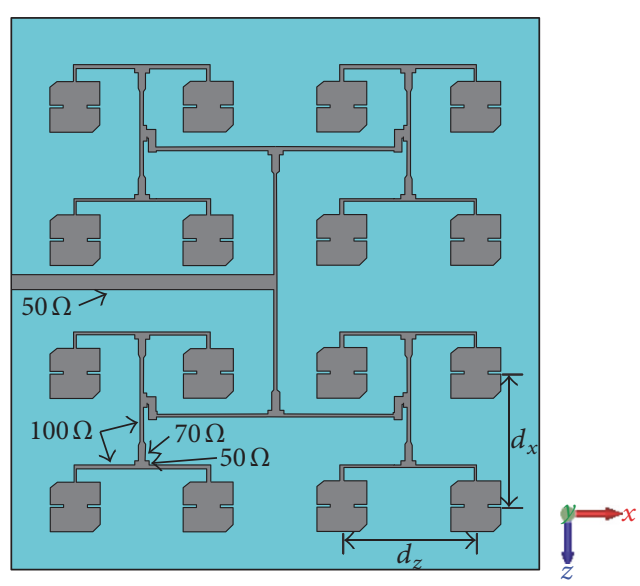

FIgURE 2: The configuration of the HTS antenna array.

2.2. Design of the Antenna Array. The configuration of the HTS antenna array is shown in Figure 2, which consists of 16 antenna elements designed in the previous section. The array is fed by a three-level T-network with quarterwave impedance transformers. As shown in Figure 2, the impedance of the feed line for antenna elements is $100 \Omega$, and the shunt impedance of two feed lines is $50 \Omega$. Hence, the transformer's impedance is set to $70 \Omega$ [13].

The parameters $d_{x}$ and $d_{z}$ are the separated distances between antenna elements along $x$ - and $z$-axes. With consideration of the mutual coupling between antenna elements and dimension of the array, $d_{x}$ and $d_{z}$ are set to $17.5 \mathrm{~mm}$, and the size of the array is $69 \mathrm{~mm} * 72.25 \mathrm{~mm}$. Using CST, the HTS antenna array is simulated. The directivity and gain of the antenna at $5.8 \mathrm{GHz}$ are $11.54 \mathrm{dBi}$ and $10.87 \mathrm{~dB}$, respectively. The radiation efficiency reaches $85.7 \%$.

2.3. Controllable Cryostat for the HTS Antenna Array. Figure 3 shows the configuration of the cryostat for the HTS antenna array. The main components of the cryostat are a Stirling refrigerator and a stainless-steel cavity. The Stirling refrigerator is used to control the temperature with a computer, while the airtight stainless-steel cavity is used to provide a vacuum for low temperature. The antenna is placed on a supporting tray in the cavity, and a radome with the relative permittivity of 4 is employed as a superstrate for sealing. The cryostat is simple and compact, and thus it is perfect for the HTS antennas. 


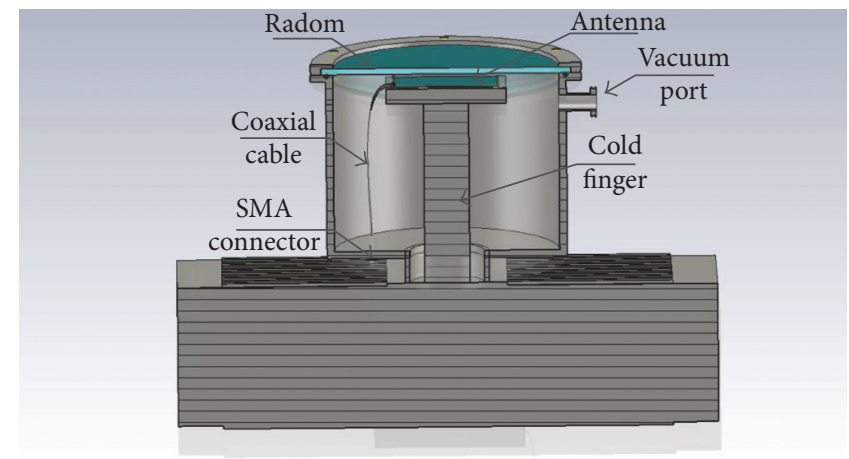

FIGURE 3: The configuration of the controllable cryostat for the HTS antenna.

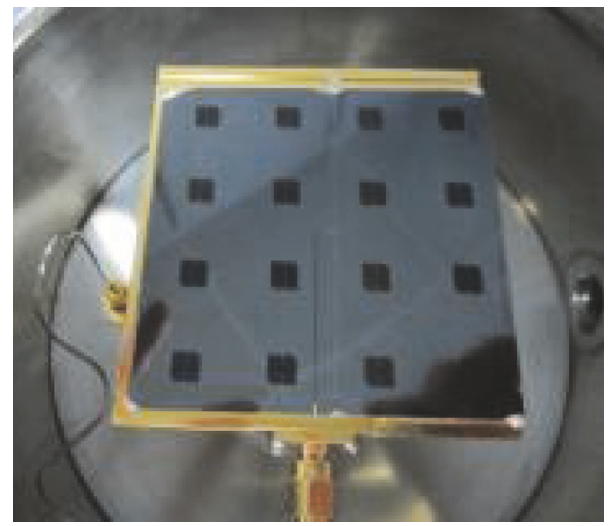

(a)

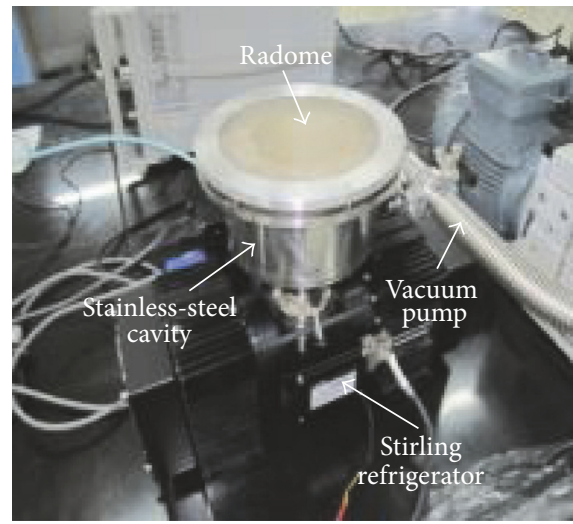

(b)

FIGURE 4: The photograph of the fabricated (a) HTS antenna array and (b) cryostat.

\section{Measurement and Antenna Performance}

The designed HTS antenna array is fabricated as shown in Figure 4(a). Figure 4(b) displays the photograph of the cryostat. The input reflection coefficient $S_{11}$ of the HTS antenna array at the temperature of $80 \mathrm{~K}$ is measured by an Agilent E8362B Vector Network Analyzer. In Figure 5, the measured and simulated input reflection coefficients agree well with each other. The measured reflection coefficient is $-15 \mathrm{~dB}$ at the working frequency of $5.8 \mathrm{GHz}$ and the $10 \mathrm{~dB}$ return loss bandwidth is $2.2 \%$ ranging from $5.75 \mathrm{GHz}$ to $5.88 \mathrm{GHz}$.

The radiation performance of the HTS antenna array is measured by a NSI system in the anechoic chamber. The radiation patterns and axial ratio of the HTS antenna array at the frequency of $5.8 \mathrm{GHZ}$ and the temperature of $80 \mathrm{~K}$ are shown in Figures 6 and 7, respectively. The beamwidths of the HTS antenna array on $X$ and $Z$ planes are $27^{\circ}$ and $30^{\circ}$, respectively, while the simulated beamwidths are $23.7^{\circ}$ and $28^{\circ}$. The axial ratio is lower than 4 at broadside.

Moreover, the circularly polarized gain of the HTS antenna array is obtained by

$$
G=10 \lg \left(10^{G_{H} / 10}+10^{G_{V} / 10}\right),
$$



Figure 5: The simulated and measured input reflection coefficients of the HTS antenna array.

where $G_{H}$ and $G_{V}$ are the measured gain of the antenna on the horizontal and perpendicular planes, respectively. Figure 8 gives the gains of the HTS antenna array at $5.8 \mathrm{GHz}$ 


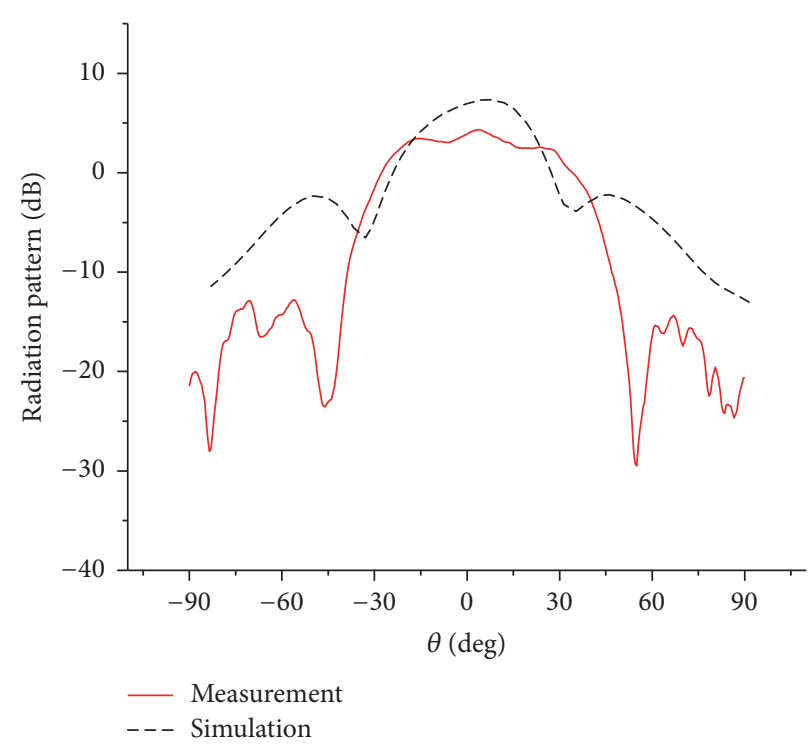

(a)

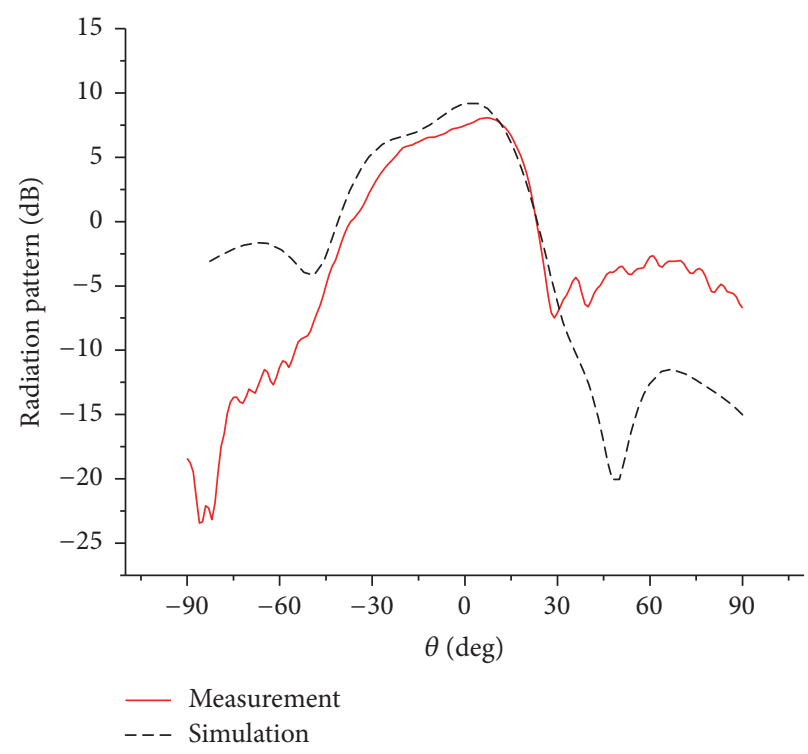

(b)

FIGURE 6: The simulated and measured radiation patterns of the HTS antenna array at the frequency of $5.8 \mathrm{GHz}$ and the temperature of $80 \mathrm{~K}$ on (a) $X$ and (b) $Z$ planes.

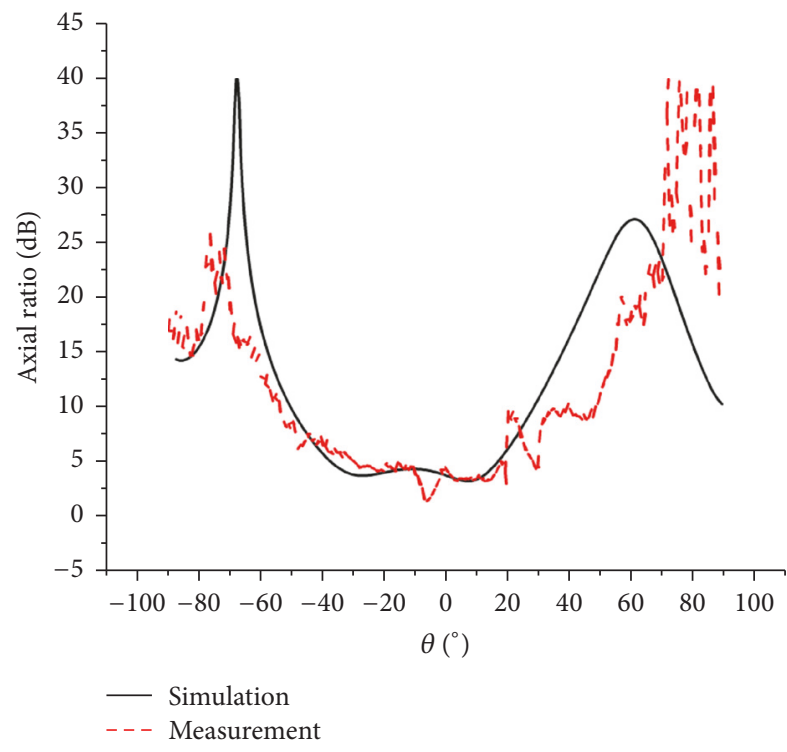

(a)

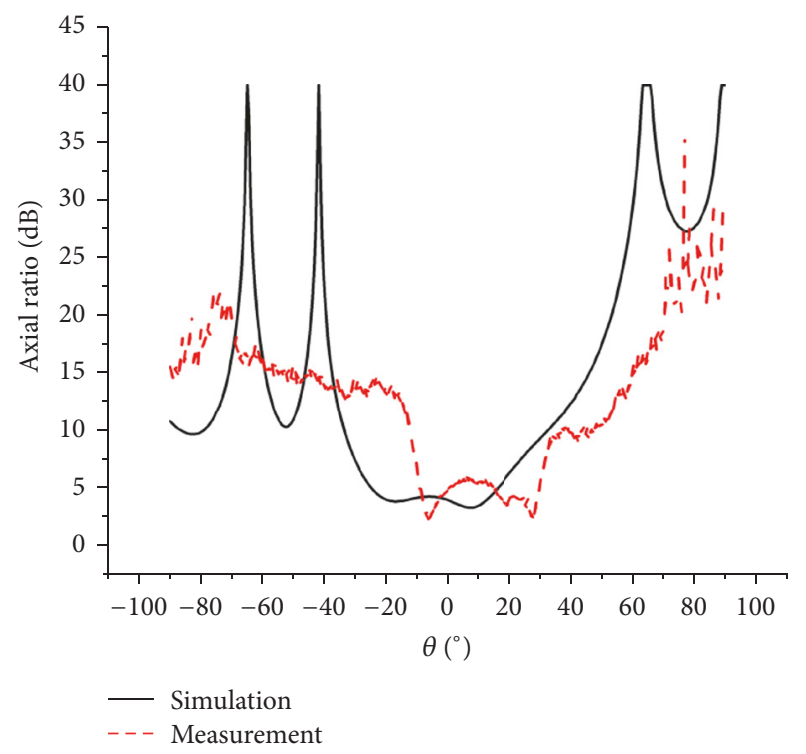

(b)

FIGURE 7: The simulated and measured axial ratio of the HTS antenna array at the frequency of $5.8 \mathrm{GHz}$ and the temperature of $80 \mathrm{~K}$ on (a) $X$ and (b) $Z$ planes.

against the temperature from $60 \mathrm{~K}$ to $90 \mathrm{~K}$. It is observed that the gain is a constant of $8.39 \mathrm{~dB}$ below the temperature of $83 \mathrm{~K}$. While the temperature exceeds $83 \mathrm{~K}$, the gain decreases dramatically.

Furthermore, a traditional conductor antenna array with the same configuration of the HTS one is simulated, fabricated and measured for comparisons. The simulated directivity and gain at $5.8 \mathrm{GHz}$ are $9.92 \mathrm{dBi}$ and $2.10 \mathrm{~dB}$, respectively. The radiation efficiency is $16.5 \%$. Figure 9 shows the radiation patterns of the traditional conductor antenna array. The measured gain is $0.32 \mathrm{~dB}$. In comparison with the traditional antenna array, the proposed array has an $8.07 \mathrm{~dB}$ improvement in the gain and a $69.2 \%$ enhancement in the radiation efficiency.

\section{Conclusion}

In this paper, a HTS microstrip antenna array with righthand circular polarization is designed for space communication. A controllable cryostat is used for the HTS antenna. Using meander slots, a broad bandwidth of the antenna is obtained. The HTS antenna array's gain and radiation 


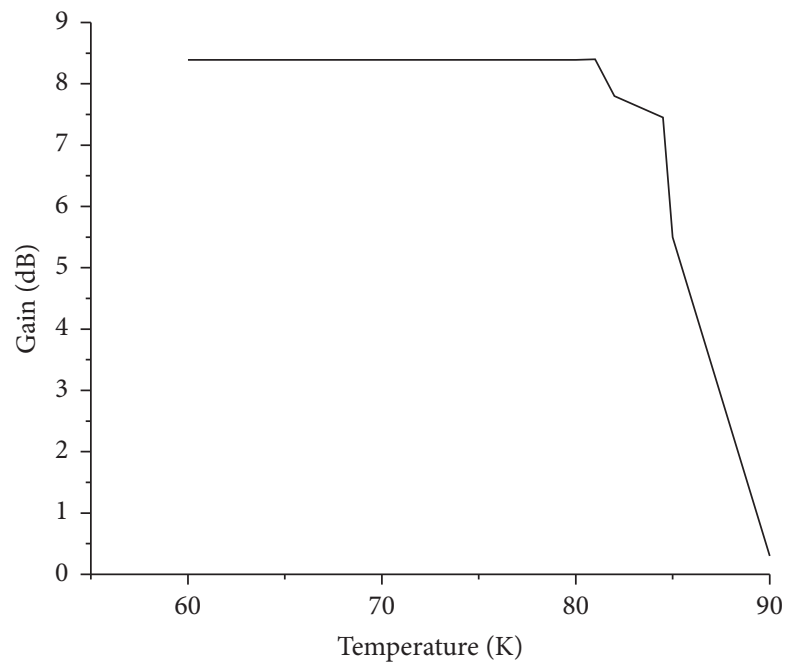

FIGURE 8: The measured gain of the HTS antenna array at the frequency of $5.8 \mathrm{GHz}$ against the temperature from $60 \mathrm{~K}$ to $90 \mathrm{~K}$.

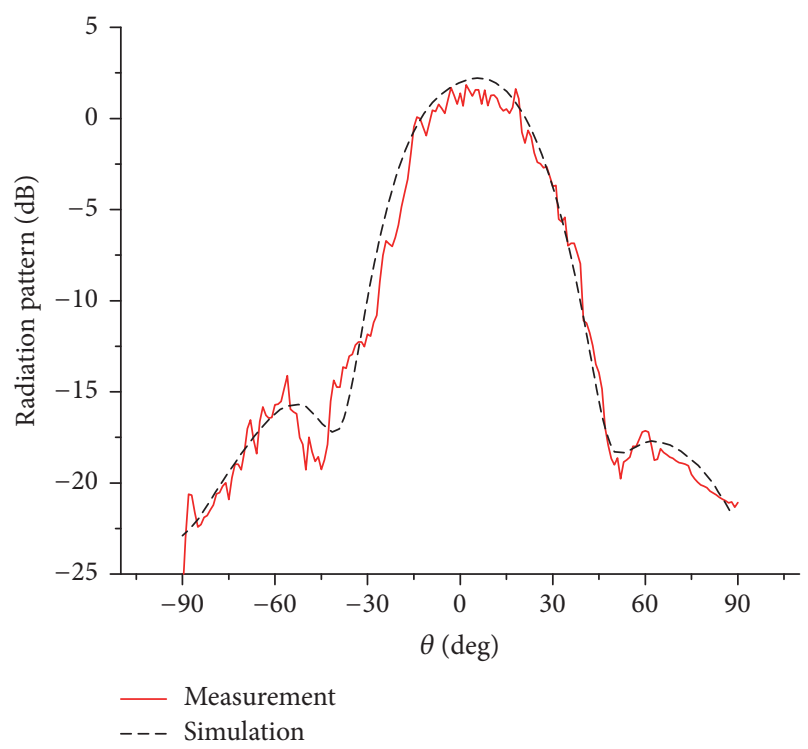

(a)

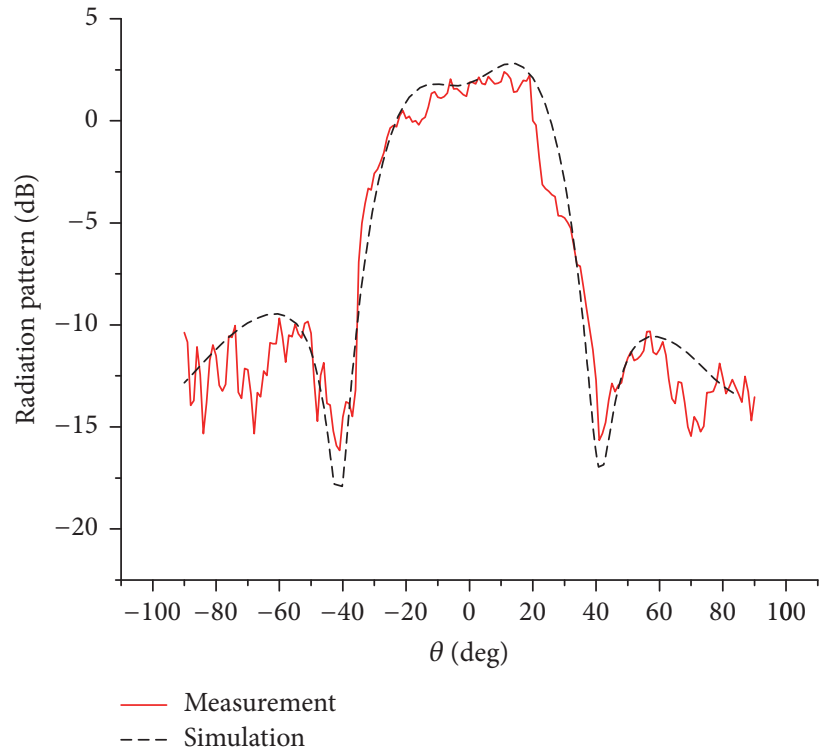

(b)

FIGURE 9: The simulated and measured radiation patterns of the traditional conductor antenna array at the frequency of $5.8 \mathrm{GHz}$ on (a) $X$ and (b) $Z$ planes.

efficiency are $8.39 \mathrm{~dB}$ and $85.7 \%$, respectively. In comparison with a traditional conductor antenna array having the same configuration, $8.1 \mathrm{~dB}$ and $69.2 \%$ improvements in antenna gain and radiation efficiency are achieved, respectively. The HTS antenna array shows more excellent performances than the traditional one, which has the potential in the space communication.

\section{Conflicts of Interest}

The authors declare that there are no conflicts of interest regarding the publication of this paper.

\section{Acknowledgments}

This work is supported by the Defense Industrial Technology Development Program of China (Grant no. JCKY2016110B001).

\section{References}

[1] K. Krishen and A. Ignatiev, "Future superconductivity applications in space-a review," in Proceedings of the World Congress on Superconductivity, pp. 141-154, Houston, TX, USA, 1988.

[2] R. Garg, Microstrip Antenna Design Handbook, Artech House, 2001. 
[3] J. Angel, D. D. Lozada, and S. Donglin, "Microstrip antenna for satellite communications," in Proceedings of the 8th International Symposium on Antennas, Propagation and EM Theory, ISAPE 2008, pp. 320-322, chn, November 2008.

[4] J. D. Morrow, J. T. Williams, M. F. Davis et al., "Circularly polarized 20-GHz high-temperature superconducting microstrip antenna array," IEEE Transactions on Applied Superconductivity, vol. 9, no. 4, pp. 4725-4732, 1999.

[5] H. Chaloupka, M. Peiniger, and A. Pischke, "Miniaturized High-Temperature Superconductor Microstrip Patch Antenna," IEEE Transactions on Microwave Theory and Techniques, vol. 39, no. 9, pp. 1513-1521, 1991.

[6] K. Itoh, O. Ishii, Y. Koshimoto, and K. Cho, "Small helical antenna made of high-temperature superconducting thick film," Journal of Superconductivity, vol. 4, no. 6, pp. 469-471, 1991.

[7] D.-C. Chung, S.-Y. Choi, Y.-H. Ko, J.-H. Lee, and M.-H. Kwak, "Circularly polarized HTS microstrip antenna array," IEEE Transactions on Applied Superconductivity, vol. 13, no. 2 I, pp. 301-304, 2003.

[8] D.-C. Chung, C.-H. Yun, K.-H. An et al., "HTS microstrip antenna array for circular polarization with cryostat," IEEE Transactions on Applied Superconductivity, vol. 15, no. 2, pp. 1048-1051, 2005.

[9] J. Morrow, J. Williams, M. Davis, D. Licon, S. Long, and J. Wolfe, "A circularly polarized HTS microstrip antenna array," in in Antennas and Propagation Society International Symposium, AP-S. Digest, pp. 760-763, 1995.

[10] Y. D. Chung, C. Y. Lee, H. K. Kang, and Y. G. Park, "Design consideration and efficiency comparison of wireless power transfer with HTS and cooled copper antennas for electric vehicle," IEEE Transactions on Applied Superconductivity, vol. 25, no. 3, 2015.

[11] M. A. Richard, K. B. Bhasin, and P. C. Claspy, "Superconducting Microstrip Antennas: An Experimental Comparison of Two Feeding Methods," IEEE Transactions on Antennas and Propagation, vol. 41, no. 7, pp. 967-974, 1993.

[12] I.-H. Kim, K.-S. Min, J.-H. Jeong, and S.-M. Kim, "Circularly polarized tripleband patch antenna for non-linear junction detector," in Proceedings of the 2013 3rd Asia-Pacific Microwave Conference, APMC 2013, pp. 140-142, kor, November 2013.

[13] L. Reinhold and B. Pavel, RF Circuit Design: Theory and Applications, Prentice Hall, Upper Saddle River, NJ, USA, 2000. 


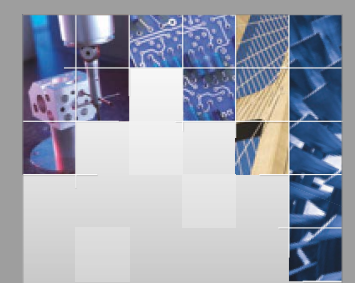

\section{Enfincering}
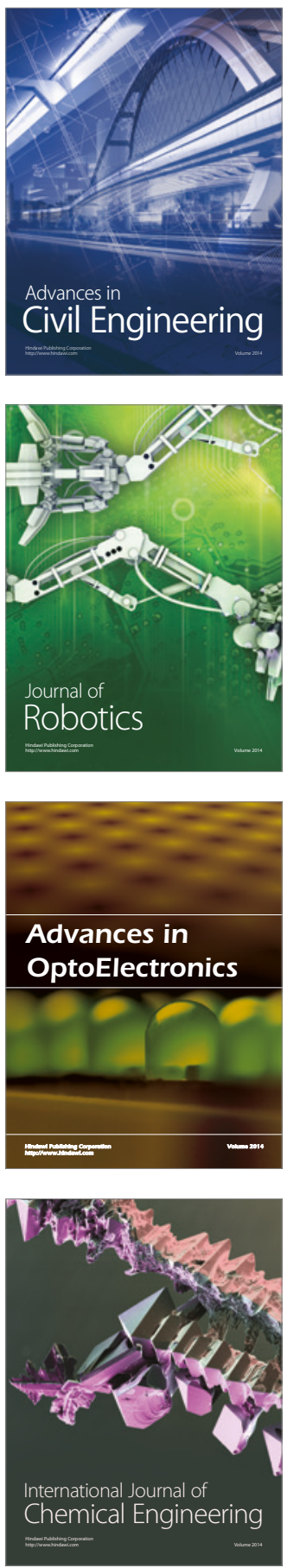

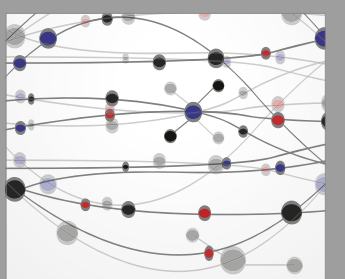

The Scientific World Journal

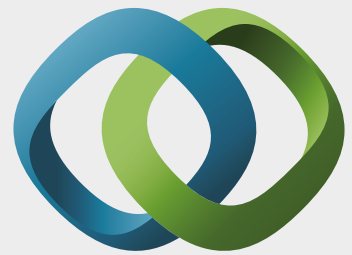

\section{Hindawi}

Submit your manuscripts at

https://www.hindawi.com
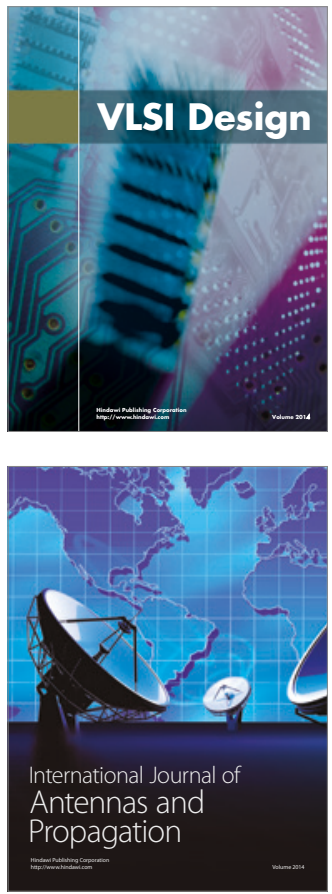

\section{Rotating}

Machinery
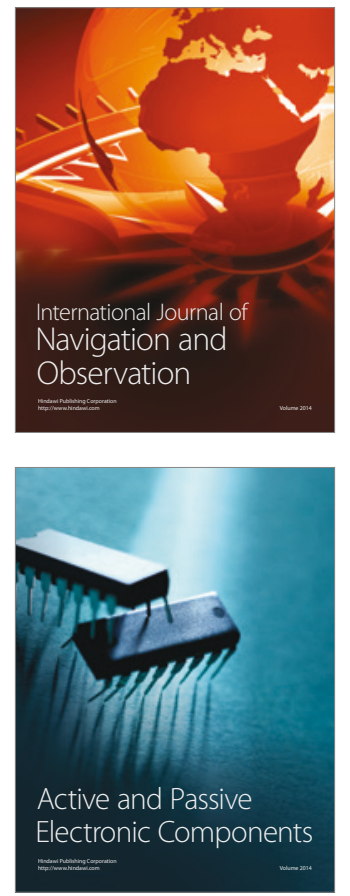
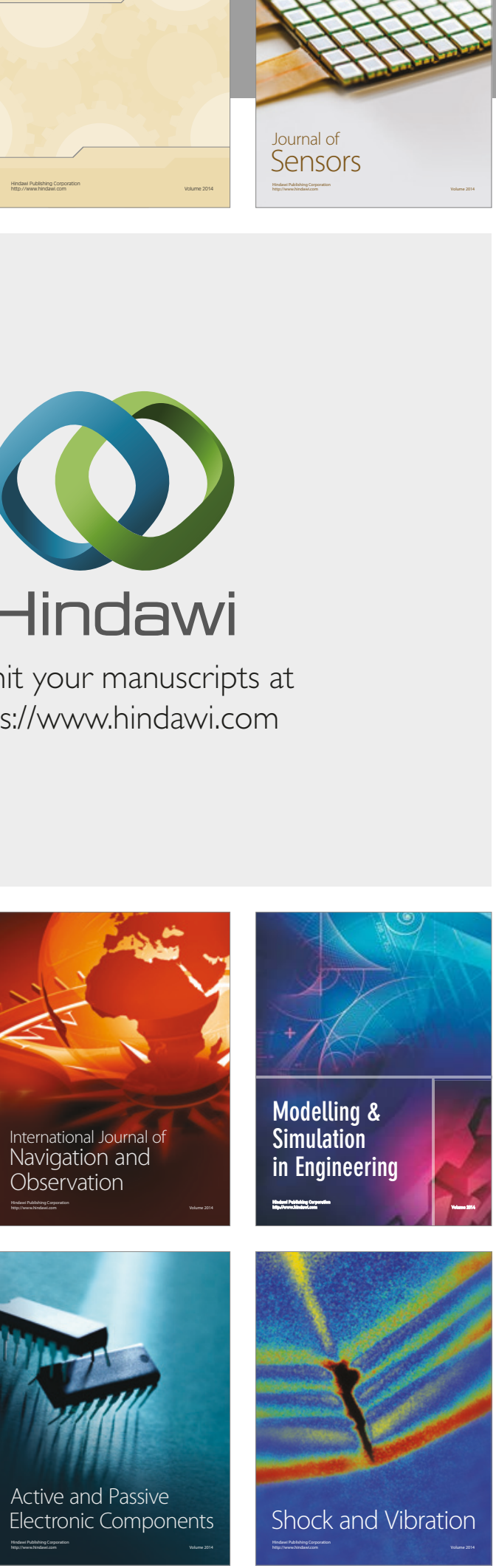
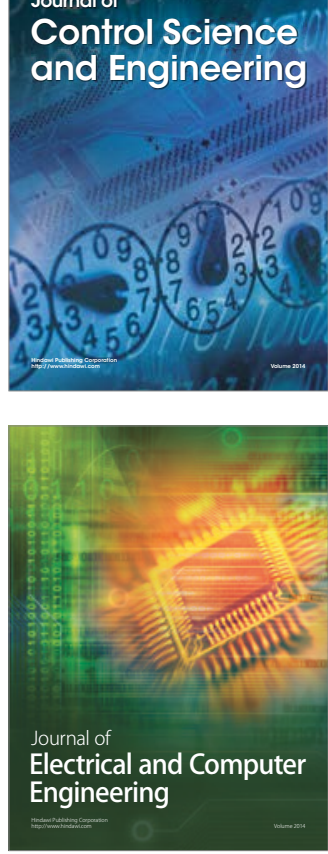

Distributed

Journal of

Control Science

and Engineering
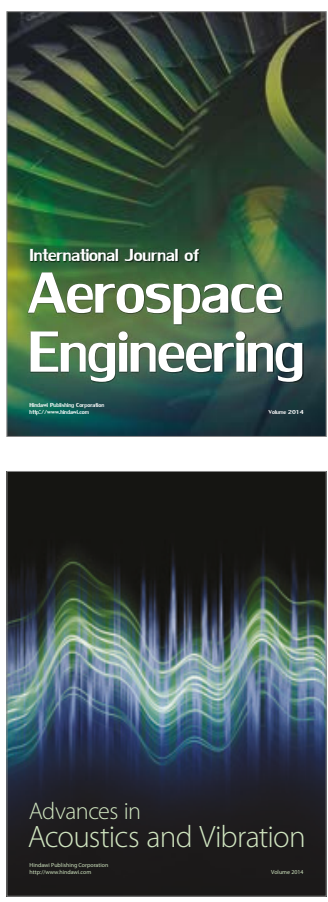

Sensor Networks 